\title{
A Generic Bio-Economic Farm Model for Environmental and Economic Assessment of Agricultural Systems
}

\author{
Sander Janssen • Kamel Louhichi • Argyris Kanellopoulos • Peter Zander • \\ Guillermo Flichman · Huib Hengsdijk · Eelco Meuter · Erling Andersen • \\ Hatem Belhouchette - Maria Blanco • Nina Borkowski - Thomas Heckelei • \\ Martin Hecker · Hongtao Li • Alfons Oude Lansink · Grete Stokstad • \\ Peter Thorne · Herman van Keulen • Martin K. van Ittersum
}

Received: 11 March 2009/Accepted: 4 November 2010/Published online: 28 November 2010

(C) The Author(s) 2010. This article is published with open access at Springerlink.com

Bio-economic farm models are tools to evaluate ex-post or to assess ex-ante the impact of policy and technology change on agriculture, economics and environment. Recently, various BEFMs have been developed, often for one purpose or location, but hardly any of these models are re-used later for other purposes or locations. The Farm System Simulator (FSSIM) provides a generic framework enabling the application of BEFMs under various situations and for different purposes (generating supply response functions and detailed regional or farm type assessments).

S. Janssen - A. Kanellopoulos · A. Oude Lansink Business Economics Group, Wageningen University,

Hollandseweg 1, $6706 \mathrm{KN}$ Wageningen, The Netherlands

S. Janssen · A. Kanellopoulos · E. Meuter $\cdot$ H. van Keulen ·

M. K. van Ittersum

Plant Production Systems Group, Wageningen University,

P.O. Box 430, 6700 AK Wageningen, The Netherlands

S. Janssen $(\bowtie)$

Alterra, Wageningen University and Research Centre,

Droevendaalsesteeg 3, 6708 PB Wageningen, The Netherlands

e-mail: sander.janssen@wur.nl

K. Louhichi - G. Flichman - H. Belhouchette

Institut Agronomique Méditerranéen de Montpellier (IAMM),

3191 route de Mende, 34090 Montpellier, France

K. Louhichi

INRA UMR Economie Publique, Avenue Lucien Bretignieres,

78850 Thiverval-Grignon, France

P. Zander · N. Borkowski $\cdot$ M. Hecker

Leibniz-Zentrum für Agrarlandschaftsforschung (ZALF),

Eberswalder Str. 84, 15374 Müncheberg, Germany

H. Hengsdijk · H. van Keulen

Plant Research International, Wageningen UR,

Droevendaalsesteeg 1, 6708 PB Wageningen, The Netherlands
FSSIM is set up as a component-based framework with components representing farmer objectives, risk, calibration, policies, current activities, alternative activities and different types of activities (e.g., annual and perennial cropping and livestock). The generic nature of FSSIM is evaluated using five criteria by examining its applications. FSSIM has been applied for different climate zones and soil types (criterion 1) and to a range of different farm types (criterion 2) with different specializations, intensities and sizes. In most applications FSSIM has been used to

\section{E. Andersen}

Forest and Landscape, University of Copenhagen, Rolighedsvej 23, 1958 Frederiksberg C, Copenhagen, Denmark

H. Belhouchette

INRA-Agro M. UMR SYSTEM, Campus de La Gaillarde, Bâtiment 272 place Pierre Viala, 34060 Montpellier, France

\section{Blanco}

European Commission, Joint Research Centre (JRC), Institute for Prospective Technological Studies (IPTS), Edificio Expo, Avda. Inca Garcilaso s/n, 41092 Seville, Spain

N. Borkowski · T. Heckelei

Institute for Food and Resource Economics, University of Bonn, Nussallee 21, 53115 Bonn, Germany

H. Li

Dalle Molle Institute for Artificial Intelligence (IDSIA), Galleria 2, 6928 Manno, Switzerland

G. Stokstad

Norwegian University of Life Sciences (UMB), Tårnbygningen, Christian Magnus Falsensvei 18, Aas, Norway

P. Thorne

University of Edinburgh, Crew Building, West Mains Road, Edinburgh, UK 
assess the effects of policy changes and in two applications to assess the impact of technological innovations (criterion 3 ). In the various applications, different data sources, level of detail (e.g., criterion 4) and model configurations have been used. FSSIM has been linked to an economic and several biophysical models (criterion 5). The model is available for applications to other conditions and research issues, and it is open to be further tested and to be extended with new components, indicators or linkages to other models.

Keywords Farming systems - Integrated assessment . Agricultural policy · Technological innovation .

Bio-economic modelling

\section{Introduction}

Agriculture uses more than $40 \%$ of the land in the European Union (EU) and agricultural activities have a great impact on the environment and countryside through resource use, labor demand, environmental externalities and landscape layout. Farmers in the EU are under increasing pressure to consider the economic outputs of their activities, but also the environmental and social outcomes, as stipulated in European Commission policy documents, such as the Nitrates Directive (EC 1991, 2002) and the Water Framework Directive (EC 2000, 2007). Bioeconomic farm models have been frequently proposed by research as tool to assess agricultural emissions to the environment (Falconer and Hodge 2001; Vatn and others 1997; Wossink and others 2001) and effects of agriculture on landscape and biodiversity (Meyer-Aurich and others 1998; Oglethorpe and Sanderson 1999; Schuler and Kachele 2003). Bio-economic farm models have also been proposed to assess the performance of different farming systems (Berentsen 2003; De Buck and others 1999; Pacini 2003) or to evaluate the Common Agricultural Policy of the EU (Donaldson and others 1995; Onate and others 2007; Topp and Mitchell 2003). Here a Bio-Economic Farm Model (BEFM) is defined as a model that links farms' resource management decisions to current and alternative production possibilities describing input-output relationships and associated externalities. BEFMs can be useful to evaluate ex-post or to assess ex-ante the impact of policy and technology change on agriculture and environment (Janssen and Van Ittersum 2007). In their review on the usefulness of BEFMs, Janssen and Van Ittersum (2007) identified a lack of re-use of these BEFMs, i.e. most models are used for a specific purpose and location only. They also largely stayed in the research domain and are not used for policy assessment. Applications of the same model for other purposes or locations are rare. An exception is the
German model MODAM that has been applied during the last decade in different German and a number of European regions (Kachele and Dabbert 2002; Meyer-Aurich and others 1998; Uthes and others 2008; Zander and Kächele 1999). Another exception is the MIDAS model (Kingwell and Pannell 1987; Morrison and others 1986) that has been repeatedly used through the last decennia on sheep-arable farms in South-West Australia (Gibson and others 2008; Kingwell and others 1995; Kopke and others 2008). In contrast, the re-use of cropping systems models for diverse purposes and locations is far more wide-spread. For example, application of the Agricultural Production Systems sIMulator (APSIM) model has resulted in 102 publications (Keating and others 2003). Also the CropSyst model (Stockle and others 1994) has been applied for different crops and environments (Confalonieri and Bocchi 2005; Pala and others 1996; Wang and others 2006). An example of an economic model that has been repeatedly used for different policy and trade questions is the Global Trade and Analysis Project (GTAP) model (Hertel 1997). Similarly, in land use change modelling, the CLUE model (Veldkamp and Fresco 1996) has been applied to many different locations at spatial scales (cf. Verburg and others 2002).

To stimulate re-use with the option for new developments at each application, we propose to develop a generic BEFM that is suitable for many different applications. It is clear that required resources for development and maintenance as well as the level of abstraction will increase with more general applicability. Therefore, the question in reality will not be "generic or not", but rather relate to an optimal degree of being generic with some remaining restrictions on applicability. Still we are of the opinion that for scientific progress the challenge is to understand and model the "generic" processes, i.e., to identify and model those processes relevant to many purposes, research questions, locations and scales. Trying to shift the balance from the current emphasis on specific BEFMs to more generic BEFMs seems correct from a scientific and efficient from an application point of view.

In our view, there are several advantages of a generic BEFM, with one common and accepted concept and implementation achieved by a community of scientists. First, applications of BEFMs are easily repeatable and reproducible by a larger community, which makes consistent and large scale applications to a great diversity of agricultural systems possible. Second, a generic model could facilitate interdisciplinary research, as research groups can cooperate more efficiently. It allows to focus on innovations and extensions in science instead of "re-inventing the wheel" for each application, which saves time and resources. Synergies in building the model across research groups may occur, each bringing their own 
specialization and features to the model. Third, a generic BEFM makes peer review easier and more transparent as referees are more likely to be familiar with the common concept of the model. Fourth, it is easier to communicate with stakeholders (e.g. end-users and researchers in other domains) about the model and to achieve stakeholder acceptance of and confidence in the model results, when only one generic concept and model needs to be explained instead of explaining a new model with every application. Fifth, the extensive data requirements of BEFMs can be standardized and managed efficiently (Janssen and others 2009a).

There may also be disadvantages of a generic model. First, it may be more difficult to maintain an overview of all assumptions of the model, as new features and extensions are added over time and are developed by somebody else. It will become necessary to invest in maintenance instead of repeated development. Manuals and peer reviewed publications are required for adequate documentation and accessibility. Maintaining an overview and ensuring transparency may be problematic in all types of models in case of poor model implementation and documentation. Second, the level of detail of processes modelled or data used in a generic model may not be appropriate for a specific application. A generic model might be less suited for a specific research question than a specifically developed model. However, a generic model might be preferred instead of specific model, because of ease of application. Third, there are risks related to the implementation in source code, i.e. lock in effects, path dependency and legacy code. Lock in effects mean that inferior programming solutions are kept, while superior solutions exist. Path dependency refers to the fact that potential progress depends on the path being followed, while alternative paths exist that yield more progress. Legacy code (Feathers 2004) is a working source code for a purpose with assumptions on its use, that is subsequently used for other purposes under different assumptions. Tests and documentation are unavailable for these new purposes and different assumptions, which makes the source code difficult or impossible to maintain, improve or use. These risks of lock in effects, path dependency and legacy code exist especially in using a specifically developed model for one application in other applications. These risks can be mitigated by initially developing the model for a range of purposes, with a clear description of assumptions made, by using version management with a description of changes between versions and by adopting a software architecture that supports replacement and extension of components without affecting the other components.

The Farm System Simulator (FSSIM) has been developed as a generic BEFM. The aim of this article is to introduce FSSIM, to describe its components and to demonstrate its generic features through describing different applications. Finally, the article discusses a set of criteria for a generic BEFM and evaluates whether FSSIM satisfies the criteria for a generic model. The second section presents the underlying concept and some specific features of FSSIM and the third section describes the components of FSSIM in more detail. The technical implementation of FSSIM is presented in the fourth section. The fifth section describes applications of FSSIM in relation to five criteria for generic models that we identified. Finally, the sixth section discusses whether FSSIM meets the criteria to be characterised as a generic model, and provides more information on the availability, maintenance and extension of FSSIM.

\section{Overview of FSSIM}

FSSIM has been developed as part of System for Environmental and Agricultural Modelling; Linking European Science and Society (SEAMLESS), which was an Integrated Assessment and Modelling research project (Van Ittersum and others 2008) that developed a computerized framework to assess the impact of policies on the sustainability of agricultural systems in the EU at multiple scales. This aim is achieved by linking models across scales, disciplines and methodologies (Van Ittersum and others 2008) (Fig. 1), and combining these models with qualitative judgements and experiences (Ewert and others 2009).

Conceptually, FSSIM serves two main purposes. The first purpose is to provide supply-response functions for socalled NUTS2-regions (EC 2008b) that can be upscaled to

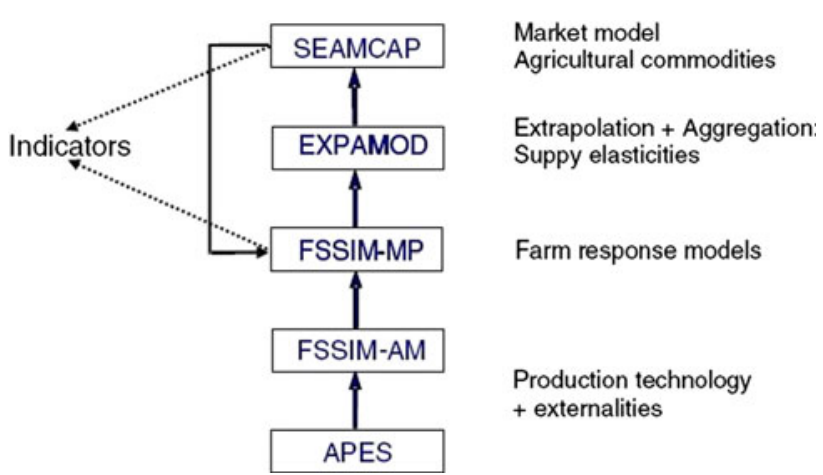

Fig. 1 The model chain in SEAMLESS (Van Ittersum and others 2008); APES Agricultural Production and Externalities Simulator, a cropping system model; FSSIM-AM Farm Systems SIMulator-Agricultural Management; FSSIM-MP FSSIM-Mathematical Programming; EXPAMOD EXtraPolation and Aggregation MODel, a regional econometric estimation model for price elasticities; SEAMCAP SEAMLESS version of the Common Agricultural Policy Regional Impact Analysis model, a partial-equilibrium market model for the agricultural sector 
EU level. NUTS stands for Nomenclature of Territorial Units for Statistics and the second level corresponds to provinces in most countries. For this purpose, FSSIM is linked to an econometric extrapolation model (EXPAMOD), as its aggregate behaviour is needed as input to a partial equilibrium market model (Fig. 1). The second purpose is to enable detailed regional integrated assessments of agricultural and environmental policies and technological innovations on farming practices and sustainability of the different farming systems. For this purpose, FSSIM can be linked to a cropping systems model (e.g., APES) to quantify agricultural activities in terms of production and environmental externalities (Fig 1.) The consequence of this dual purpose of FSSIM is that some of its applications are more data intensive than other applications.

BEFMS are usually based on mathematical programming (MP) techniques. In MP the farm is represented as a linear combination of farm activities. The concept of activity is specific to mathematical programming and incorporates the idea of "a way of doing things" (Dorfman and others 1958). An activity is a coherent set of operations with inputs resulting in the delivery of corresponding marketable products or products for on-farm use and externalities, e.g. nitrate leaching, pesticide run-off and biodiversity (Ten Berge and others 2000). An activity is characterised by a set of technical coefficients (TCs, or input-output coefficients) expressing the activity's contribution to the realisation of defined goals or objectives in modelling terms (Hengsdijk and van Ittersum 2003). Constraints are included to express farm level minimum or maximum quantities of input use or output marketing restrictions. Optimal activity levels are obtained by maximising an objective function reflecting user-specified goals, for example profit maximization, subject to the set of constraints (Hazell and Norton 1986). Standard mathematical formulations of MP models can be found in Hazell and Norton (1986).

FSSIM consists of two main components, FSSIMMathematical Programming (MP) and FSSIM-Agricultural Management (AM) (Fig. 2). FSSIM-AM comprises the activities in the BEFM, while FSSIM-MP describes the available resources, socio-economic and policy constraints and the farm's major objectives (Louhichi and others 2010b). Both components are jointly configured to simulate a mathematical problem of resource allocation depending on the farm type, agri-environmental zones, research question and data availability.

The aim of FSSIM-AM is to describe current activities, generate alternative activities and quantify the activities through all the required technical coefficients. Alternative activities are new activities or activities currently not widely practiced in the study area, and include technological innovations and newly developed cropping or husbandry practices (Hengsdijk and Van Ittersum 2002; Van Ittersum and Rabbinge 1997). Based on the farm typology, the Technical Coefficient Generator (TCG) quantifies inputs and outputs for arable, livestock or perennial activities or combinations of activities. These activities can be simulated by a cropping system model such as the Agricultural Production and Externality Simulator (APES: Donatelli and others 2010) or CropSyst (Stöckle and others 2003) in terms of production and environmental effects. The quantified activities in terms of inputs and outputs are assessed in FSSIM-MP with respect to their contribution to the farms and policy goals considered (Fig. 2)

The outputs of FSSIM at farm scale are allocated areas with crop, grassland and perennial activities, or numbers of animals with livestock activities depending on the farm type considered. On the basis of optimal activity levels, different types of indicators can be calculated such as economic indicators for income, gross production and the share of subsidy in income, and environmental indicators for nitrate and pesticide leaching and erosion (Alkan Olsson and others 2009).

In order to perform with/without assessment of technological innovations, policies or societal trends, a base year, baseline and one or more counterfactual experiments have to be specified for simulating a research question with FSSIM. Historic production patterns (e.g., land use and animal levels) of the base year are used to calibrate the model, e.g., ensuring that observed production patterns can be reproduced. Different calibration procedures have been incorporated and model behaviour is evaluated based on the percentage of absolute deviation (Kanellopoulos and others 2010). The percentage absolute deviation (PAD) is defined as the absolute deviation between simulated and observed activity levels per unit of actual activity level. These calibration procedures have been tested in a backcasting experiment based on historical data by Kanellopoulos and others (2010). Subsequently, a future baseline experiment is run using accepted and implemented policies. Results of this baseline experiment are used as benchmark for results of counterfactual experiments with the same time horizons. By using such calibration procedures and experimental set up, the overall aim of FSSIM is achieved, which is to simulate the actual farm responses through realistic and validated (e.g., positive) modelling (Flichman and Jacquet 2003).

\section{Components of FSSIM}

\section{FSSIM Mathematical Programming}

FSSIM-MP (Louhichi and others 2010b) is a model maximising a farm's utility function subject to a number of resource and policy constraints. The model can be 
Fig. 2 The structure of FSSIM and its outputs. FSSIM consists of two main parts, i.e. the FSSIM-Agricultural Management (AM) component representing activities of the BEFM and the FSSIMMathematical Programming (MP) component representing the objective function and constraints of the BEFM

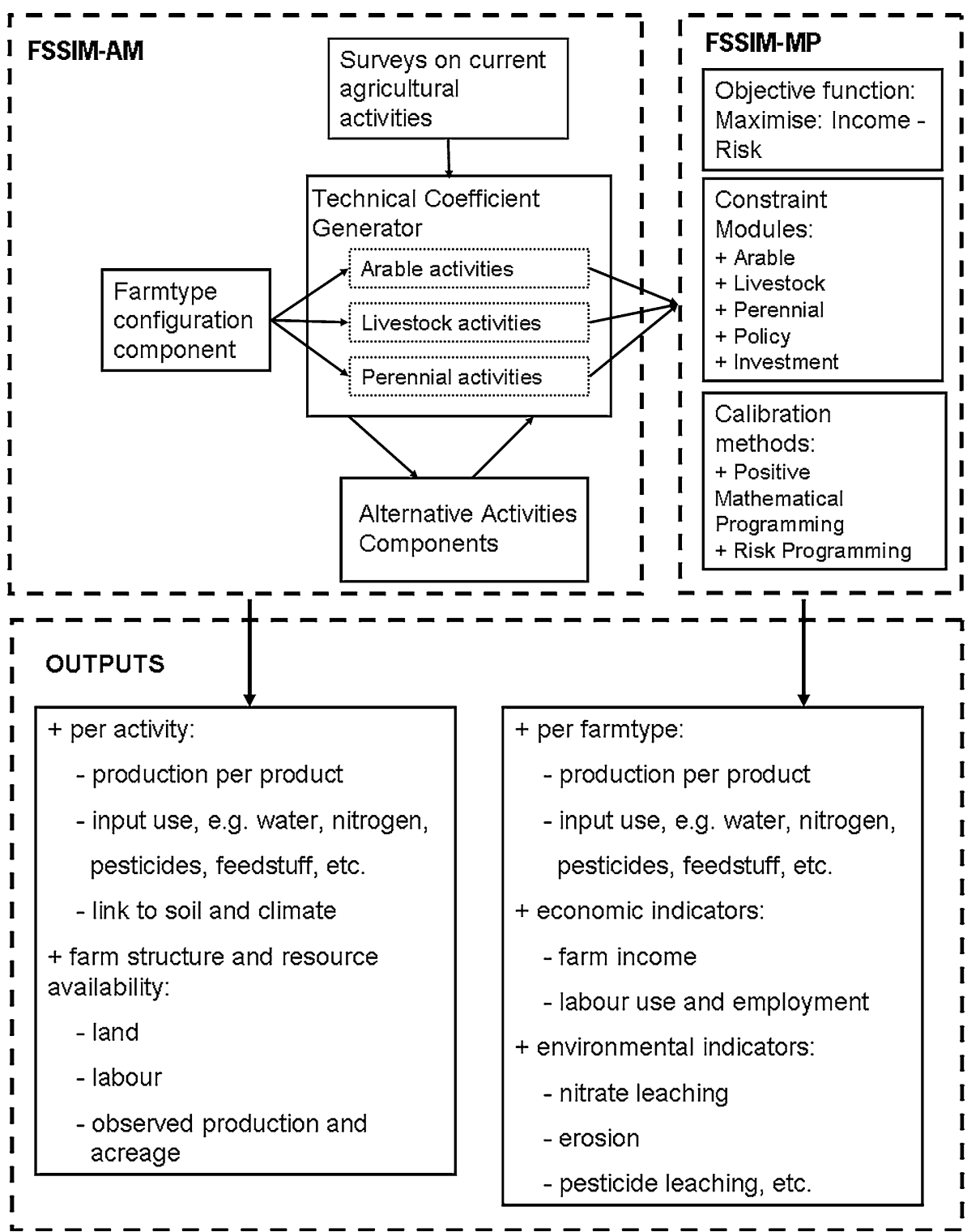

characterised as a static positive, risk programming approach. A positive model means that its empirical applications exploits realistically the observed behaviour of economic agents. A static model does not include a time step in the model. Although the model is static, the input and output coefficients of the agricultural activities take temporal interactions into account as "crop rotations" and "dressed animal" instead of individual crops or animals (Hengsdijk and van Ittersum 2003).

Risk is taken into account with the Mean-Standard deviation method in which expected utility is calculated based on the expected income, the farm specific risk aversion parameter and the standard deviation of income (Freund 1956; Hazell and Norton 1986). Effectively, it is assumed that farmers make their decisions in order to maximize expected income minus some measure of its variability caused by yield and price variations. Expected income is calculated as a farm's gross margin subject to a set of resource and policy constraints. Total gross margin is defined as total revenues including sales from agricultural products and compensatory payments (subsidies) minus total variable costs from crop and animal production. In the risk programming expected utility is maximised to find the optimal linear combination of activities from the full set of activities. The definition of activities is done in FSSIM-AM and is usually based on the assumption of average weather conditions, as uncertainty in yields and prices is incorporated through the risk programming approach.

FSSIM-MP consists of components (i.e. groups of equations) that capture the agricultural activities (e.g., arable, livestock, perennials) and components for inclusion of alternative policies, calibration procedures (Positive Mathematical Programming (PMP)), risk and trend analysis (Table 1). The principal policy instruments implemented in 
Table 1 Components and their role in FSSIM-MP

\begin{tabular}{|c|c|}
\hline Title component & Role and functionality \\
\hline $\begin{array}{l}\text { Integrative } \\
\text { component }\end{array}$ & $\begin{array}{l}\text { Solve the components together and manage mode } \\
\text { execution }\end{array}$ \\
\hline Annual crops & $\begin{array}{l}\text { Resource constraints (e.g., land, labour, irrigable } \\
\text { land), production, revenues and income from } \\
\text { arable activities }\end{array}$ \\
\hline Livestock & $\begin{array}{l}\text { Resource constraints (e.g., feed availability and } \\
\text { requirement, stable size, concentrate purchases, } \\
\text { labour), production, revenues and income from } \\
\text { livestock activities }\end{array}$ \\
\hline $\begin{array}{l}\text { Perennial } \\
\text { activities }\end{array}$ & $\begin{array}{l}\text { Resource constraints (e.g., replacement and } \\
\text { investment, land, labour, irrigable land), } \\
\text { production, revenues and income from perennial } \\
\text { activities }\end{array}$ \\
\hline Policy & $\begin{array}{l}\text { Price and market support-policies, set-aside } \\
\text { schemes, quota schemes, production and income } \\
\text { support policies, tax and penalties, cross- } \\
\text { compliance and agri-environmental measures }\end{array}$ \\
\hline PMP & Different PMP variants for exact calibration \\
\hline Risk & Risk as aversion from yield and price variation \\
\hline Trend & $\begin{array}{l}\text { Yield and prices trends between base year and } \\
\text { baseline experiment }\end{array}$ \\
\hline
\end{tabular}

FSSIM-MP (Louhichi and others 2010a) are price and market policies, set-aside schemes, quota schemes, production and income support policies, taxes and levies, cross-compliance and agri-environmental measures (Table 1). Policy instruments in FSSIM-MP are modelled either as part of the objective function (e.g., premiums as monetary incentives), or by including them as constraints (e.g., set-aside and quota schemes). The calibration component, consists of four different options with different data requirements to enable the analysis of a variety of policy questions: (i) calibration on the risk aversion parameter using the mean standard deviation approach. This procedure involves multiple model runs with different values of risk aversion and multiple comparisons of the simulations with observed historical data. The value of risk aversion that gives the lower PAD value is used for scenario testing. (ii) The standard PMP approach (Howitt 1995) uses one year observations on activity levels to recover non-linear costs due to limited managerial and machinery capacity. Exact calibration is achieved. (iii) The Röhm and Dabbert (Röhm and Dabbert 2003) PMP variant uses additional historical data on agricultural management to account for substitution and compensation between similar activities improving the model's forecasts. (iv) The Kanellopoulos and others (2010) PMP variant uses information on own price elasticities to improve justification of some assumptions of the standard PMP approach and improve the forecasting performance of the model. Depending on the data availability and the type of policy question the user can choose the most appropriate calibration procedure.
These components are solved simultaneously and they are managed by an integrative component (Table 1), containing the objective function and the common constraints. Thanks to its modularity, FSSIM-MP provides the capability to add and remove components (and their corresponding constraints) in accordance with the needs of the simulation experiment and to control the flow of data between the database and the software tools. FSSIM-MP has been programmed in the General Algebraic Modelling System (GAMS 2008).

\section{FSSIM Agricultural Management}

\section{Current Agricultural Management}

A detailed knowledge of current agricultural management is required to reproduce production patterns in the base year and to assess the impact of short term policy changes, where farmers response is based on their current technologies. Current agricultural management serves as input for the definition of alternative activities. These current activities represent the inputs and outputs of actual farming practices for average weather conditions (Zander and others 2009). Diversity in actual farming practices, and thus in inputs and outputs of activities is large. This diversity in activities can either be captured by average or typical current activities. Average activities represent the mean of activities carried out on a representative sample of farms, while typical activities are described on the basis of representative activities such as available in farm management handbooks or extension brochures. Information on current activities can be based on observed data or expert knowledge. In the SEAMLESS project, a lack of data and information on agricultural activities at European level was identified, especially with respect to non-economic data. For example, the Farm Accountancy Data Network (EC 2008a) provides aggregate costs and aggregate input use for the whole farm but not specified per crop or animal type and without a temporal distribution. Therefore, two dedicated surveys were developed as part of the SEAMLESS project (Zander and others 2009). A detailed survey was carried out in five EU regions (Brandenburg, Andalucia, Midi-Pyrénées, Flevoland and Zachodniopomorskie) that collected data for typical current arable activities on input quantities, timing of input use, crop rotations, machinery and labour use, and associated costs. The detailed survey was conducted by regional experts, who work regularly with farmers. A so called "simple survey" was conducted to collect a reduced data set in $16 \mathrm{EU}$ regions for arable, livestock and perennial activities comprising economic variables (e.g., product costs and prices), yields, composition of rotations and some aggregate physical variables describing input use (e.g., nitrogen use per crop and total 
medicine costs per animal) (Zander and others 2009). The simple survey does not contain information on detailed management variables, i.e., frequency and timing of input use. The regions were selected to represent the diversity of farm types in different bio-physical endowments across EU-25. The regions selected are administrative regions, but the information in the surveys is linked to different agromanagement-zones (1-5 per region) within a region. The simple survey was conducted by scientists working in the region supported by statistical data and farm management handbooks. For application in new regions these data on current activities need to be made available.

\section{Alternative Agricultural Management}

Few BEFM applications include technically feasible alternative activities and if they are used they are based on expert judgment with the risk of missing out suitable alternatives (Dogliotti and others 2003; Hengsdijk and Van Ittersum 2002; Janssen and Van Ittersum 2007). In FSSIM two specific components are available generating systematically alternative crop rotations and crop management options. The Production Enterprise Generator (PEG) is a version of ROTAT (Dogliotti and others 2003) that generates crop rotations based on best agronomic practices formalised in crop and rotation suitability criteria, for example the maximum frequency of specific crops in a rotation to avoid the build up of soil born diseases. The Production Technique Generator (PTG) generates alternative crop management for entire rotations based on userdefined rules for water, nutrient, conservation, weed, pest and disease management. For example, the amount of nitrogen fertilizer is based on calculated crop requirements to realize current yields instead of the amount of nitrogen fertilizer in the simple survey. The methods to generate alternative activities developed in the PEG and PTG may be extended for livestock and perennial activities.

\section{Technical Coefficient Generator for Arable Activities}

Technical coefficient generators (TCGs) (Hengsdijk and van Ittersum 2003) are algorithms to process data and information into technical coefficients directly usable by a mathematical programming model (e.g., FSSIM-MP) and cropping systems models (e.g., APES). The Current Activities component (CAC) of the TCG processes survey data into compatible inputs for FSSIM and links them to regional farm types, while calculating an average over several years for the observed cropping pattern, product price and yield variability for these farm types using data from the FADN-based farm typology (Andersen and others 2007). The Simple Management Translator (SMT) of the TCG processes simple survey data into sets of inputs required for running a cropping system model based on expert-based management rules (Oomen and others 2009). In the SMT, the aggregated physical input use from the simple survey is converted into a number of crop management events characterized by amounts, timing rules, machinery usage and working depths. Expert crop-specific management rules have been developed for sowing, harvesting, tillage, nutrient and water management. For example, if the simple survey data indicates that $150 \mathrm{~kg} \mathrm{~N} / \mathrm{ha}$ is applied in a wheat crop, the management rule determines that this amount is applied in three splits, i.e. $30 \%$ in the first split at beginning of tillering, $40 \%$ in the second at ear initiation and $30 \%$ of the total in the last split at development of the last leaf. When detailed crop management data is available, for example through the detailed survey, the conversion of the simple management data through expert rules in the SMT is not needed.

\section{Technical Coefficient Generator for Livestock Activities}

The TCG also prepares quantified livestock activities for dressed animals (Thorne and others 2008), i.e., a combination of a mother-animal and its replacement in the form of a number of young animals. The types of livestock considered are dairy and beef cattle, sheep and goats. TCG for livestock activities characterizes livestock activities in terms of energy, protein and fill units requirements (Jarrige and others 1986) according to the French feed evaluation system (Beaumont and others 2007; Jarrige 1988, 1989). These energy, protein and fill unit requirements of livestock activities have to be met in FSSIM-MP with the energy, protein and fill units of the feed resources available at farm, such as grass fodder, grass-silage, hay and feed production on arable land (e.g. fodder maize and fodder beets). Energy, protein and fill unit contents of feed resources are either based on Jarrige (1988) or calculated according to static relationships with on the one hand grassland yields and associated nitrogen input levels and on the other hand energy, protein and fill unit contents (Thorne and others 2008).

\section{FSSIM Graphical User Interface}

One of the features that could stimulate the use of generic BEFMs by a larger community and that benefits from the modular set up is an easy to use and accessible graphical user interface (GUI), which is specifically developed for FSSIM (Meuter and others 2009). This FSSIM GUI is a user-friendly interface allowing users to initialize, run and modify data for simulations with FSSIM-AM (Meuter and others 2009) and this data can then be used in FSSIM-MP. The functionality is primarily targeted at users with little to 


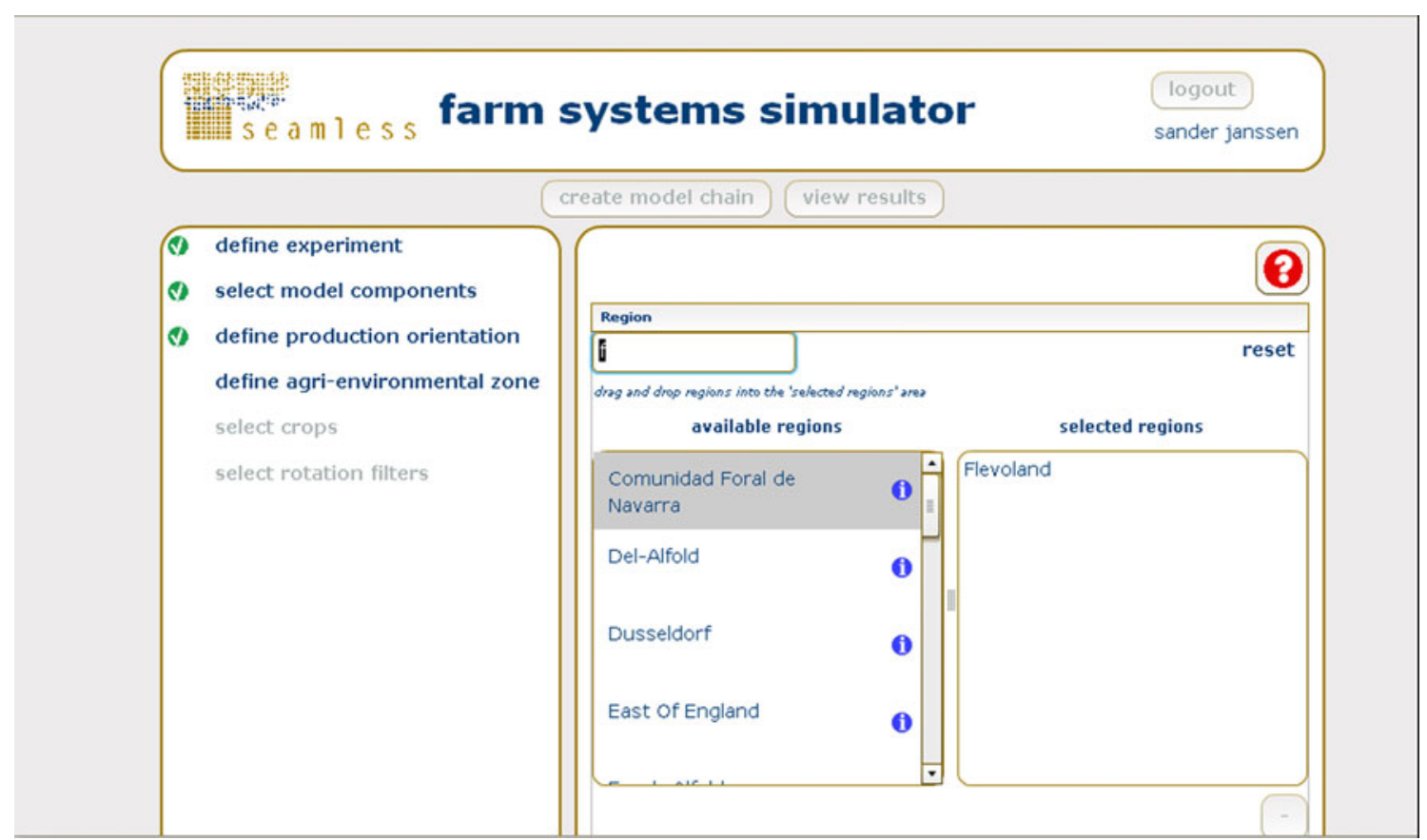

Fig. 3 A screenshot of the screen allowing the user to select the region of relevance of the FSSIM-GUI

no experience in the use of BEFMs. In the GUI, the user specifies model experiments to select and configure the components available in FSSIM-AM, because usually not all available components are needed for a specific experiment. Depending on the selected components, the components are further configured on the basis of the study region (Fig. 3), farm type, available agri-environmental zones and crops. In addition, parameter values for prices and policy instruments need to be set by the user. The FSSIM-GUI is web-based, which makes the application easily accessible for the research and user community and allows the application to keep track of its users. Outputs from the model experiments can be downloaded for further processing.

\section{Technical Design of FSSIM}

An adequate technical design is required to achieve a conceptually generic model, that is relatively easy to use, maintain and extend. The technical design of FSSIM is based on the theory of software components, semantically aware components and multi-tiered application. The division of a model in software components supports the modularity of FSSIM in the conceptual components presented in the previous sections (Fig. 4). The components are made semantically aware. Semantically aware components use a common "dictionary" of shared data types to ensure meaningful, consistent and explicit exchange of information between FSSIM components. Finally, multitiered applications help to separate common operations such as data storage and access, visualization and execution of the model from the implementation of the model in source code, thereby allowing modelers to focus on model implementation (Evans 2003; Knapen and others 2007) (Fig. 4). The implementation based on these three theories, i.e. software components, semantically aware components and tiered applications, ensures that the FSSIM model can be divided into parts that can be developed, maintained and extended simultaneously with an adequate data-exchange between these parts.

Software components (Szyperski and others 2002) mean that a model (or program) can be dissected in distinct autonomous parts (e.g. a component) that communicate with other components in the model and provide services to other components or a model. For something to be called a software component, it must have a clearly defined interface, be able to communicate with other components, encapsulate its inner workings, be non-context specific and independently re-usable in other situations (Szyperski and others 2002). FSSIM is divided into two main components, i.e., FSSIM-MP and FSSIM-AM which each are divided into smaller components, for example, the livestock component of FSSIM-AM generating livestock activities and the policy component of FSSIM-MP that models agricultural EU policies. This design allows to use, replace and improve FSSIM components independently facilitating model development and maintenance of the model by different modelers.

The interfaces of FSSIM components, i.e., the inputs and outputs of a component are annotated and described 
Fig. 4 Technical design of FSSIM. The tiers are presented in rectangles with the FSSIM component inside the domain tier. Arrows indicate information exchange among tiers

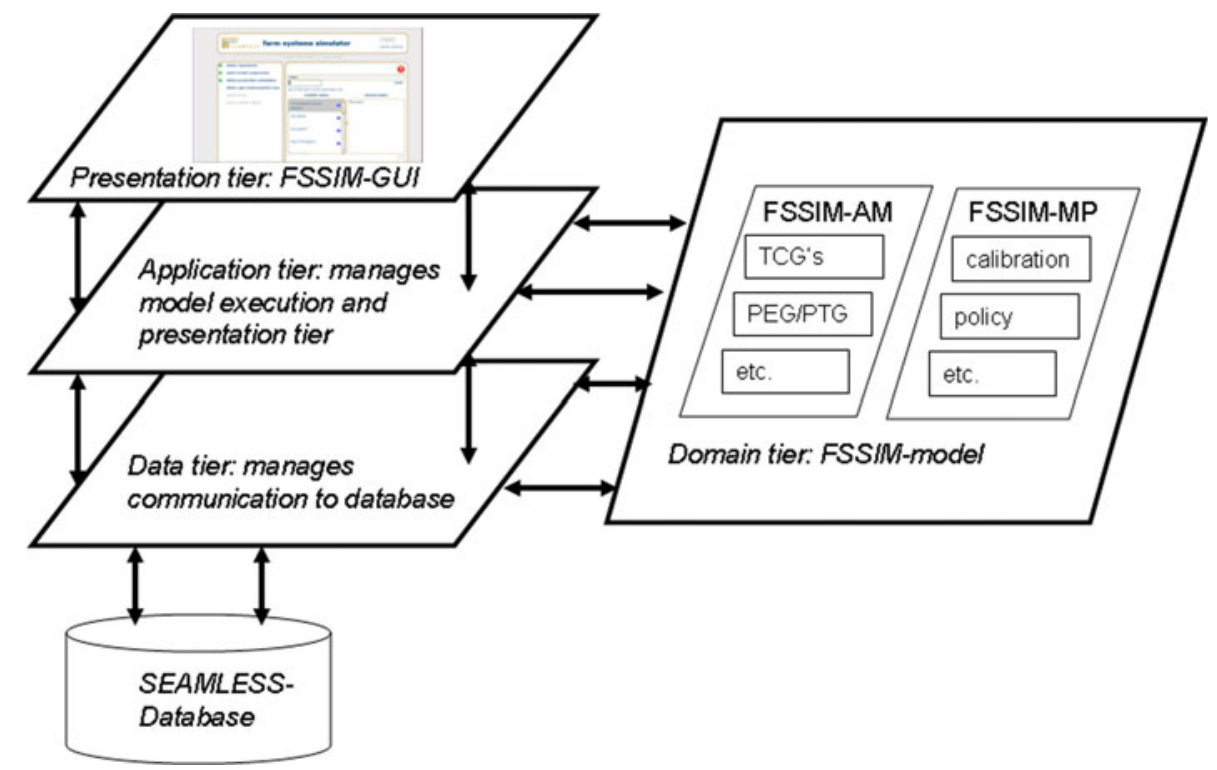

explicitly in an ontology (Athanasiadis and Janssen 2008) which can be understood as a shared dictionary. In computer science, an ontology is considered to be the specification of a conceptualization (Gruber 1993). Such a conceptualization is expressed in a machine readable format, for example the Web Ontology Language (OWL) (McGuinness and Van Harmelen 2004). The use of an ontology facilitates clear definitions for loosely integrated models in an open software environment ( $\mathrm{Li}$ and others 2007; Rizzoli and others 2008). The ontology with the component interfaces functions as a common dictionary and ensures consistent definitions of concepts and data types across components. The ontology helps to link internal FSSIM components and to link FSSIM to models from other domains. Component modelers have to interact to clarify the interfaces of each of the components. These ontologies for FSSIM are available as OWL files on http://ontologies.seamless-ip.org and this dictionary can be used in future developments of BEFMs as a common reference point.

The tiers in FSSIM consist of presentation tiers, a data tier, an application tier and domain tier. The presentation tier is the graphical user interface (GUI), which obtains user-input and presents the model results. Two different presentation tiers are linked to FSSIM, the SEAMLESSIntegrated Framework GUI and the FSSIM-GUI. The FSSIM-GUI is used to operate FSSIM as standalone model independent of other SEAMLESS models. In SEAMLESSIF, FSSIM is integrated with other models and is run as part of a model chain managed by the SEAMLESS-IF GUI (Fig. 1). The FSSIM application tier manages the interaction between different tiers, especially the model execution from the presentation tier. FSSIM forms its own domain tier. The data tier handles data requests by the application tier or domain tier and communicates with the SEAMLESS database to retrieve this data. Finally, the domain tier consists of the components of FSSIM and offers functionality of FSSIM to the other layers. Advantage of a tiered application is the separation of roles and modularity, as changes in one tier do not directly have to affect other tiers.

\section{Applications}

FSSIM has been applied in a number of cases over the past years by different research groups for two purposes, i.e., micro-macro analysis and regional integrated assessment.

\section{Application for Micro-Macro Analysis}

FSSIM was used to provide input to supply-response functions at NUTS2 level that were upscaled to EU level. In this context, FSSIM was applied to 13 regions and 55 arable farm types throughout the EU to obtain values for price elasticities of different crop products. A price elasticity is the percentage change in supply as a results of one percent change in price. Table 2 provides an example of FSSIM result in the form of price elasticities for soft wheat in five regions. In Kanellopoulos and others (2010), a description of the application to two of these 13 regions can be found, i.e., Flevoland in the Netherlands and MidiPyrénées in France. FSSIM is used according to a standardized and automated procedure in each region. First, data are retrieved from FADN (EC 2008a) and from the simple survey on agricultural management for each farm type in a region. Second, these data are processed in an automated way through FSSIM-AM to prepare the 
Table 2 Price elasticities for soft wheat for five different regions as derived from simulations by FSSIM (Kanellopoulos and others 2010; Pérez Domínguez and others 2009)

\begin{tabular}{ll}
\hline Region (land) & $\begin{array}{l}\text { Price elasticity } \\
\text { for soft wheat }\end{array}$ \\
\hline Andalucía (Spain) & 0.22 \\
Midi-Pyrénées (France) & 4.37 \\
Poitou-Charentes (France) & 2.36 \\
Brandenburg (Germany) & 0 \\
Flevoland (Netherlands) & 2.26 \\
\hline
\end{tabular}

technical coefficients, e.g. specifications of relevant activities and farm and policy parameters. Subsequently FSSIM-MP optimizes the objective using the region-specific and farm-specific sets of activities and constraints with an automated calibration procedure (Kanellopoulos and others 2010). By using a standardized and automated procedure, the application is repeatable and consistent over different farm types. Region-specific characteristics of farm types and technologies differentiated by biophysical conditions beyond those implied by the standard data sources could not be taken into account.

\section{Applications for Regional Integrated Assessment}

Six detailed regional assessments have been done using FSSIM involving different farm types (e.g., arable and livestock), different scales (e.g., individual farm types, catchments and regions), different geographical locations (e.g., North, East, Western and Southern Europe, Africa) and using different components to estimate yields and environmental effects of activities (e.g., models and expert knowledge). In some of these applications, adjustments to FSSIM-AM or alternative procedures to estimate technical coefficients have been made dependent on the availability of a calibrated cropping systems model and detailed data for regions or farm types.

In one application, FSSIM and CropSyst (Stöckle and others 2003) were jointly applied to assess the impacts of the Nitrates Directive (EC 1991) on three arable farm types in the French Midi-Pyrénées region (Belhouchette and others 2010). Table 3 provides values for the indicators farm income and nitrate leaching for the baseline and counterfactual "Nitrates Directive" experiment as an example of results of a regional integrated assessment. Louhichi and others (2008) also applied FSSIM-MP in four farm types in the Sikasso region (Mali) evaluating the impacts of improved cropping practices and introduction of organic cotton. Majewski and others (2009) applied FSSIM to several arable farm types in the Zachodniopomorskie region in Poland to investigate the impacts on economic indicators and cropping pattern due to changes in farm quotas and the introduction of biofuels. In a catchment in Scotland, Mouratiadou and others (2010) used outputs of the process-based nitrogen simulation model NDICEA (Van der Burgt and others 2006) in FSSIM-MP to assess impacts of EU's 2003 reform of the Common Agricultural Policy (EC 2003) on economic and water quality indicators of two farm types. The application to livestock farming is an assessment of the consequences of an increase in milk quota and concentrate prices on dairy farms in Auvergne, France and in Flevoland, Netherlands (Louhichi and others 2009).

The impacts of alternative irrigation and nutrient management on crop allocation, farm income and environmental indicators is investigated using FSSIM-MP, FSSIM-AM and APES for Flevoland in the Netherlands (Janssen and others 2009b). In this application, a standardized and automated procedure processes data of arable activities from the simple survey and FADN to create inputs for a cropping systems model of which the results are subsequently provided to FSSIM-MP.

\section{Is FSSIM Generic, Usable and Extensible?}

\section{Criteria for a Generic BEFM}

The applications of FSSIM are evaluated using five criteria defined for generic BEFM (Table 4). The first criterion is that the BEFM must be relevant for a range of

Table 3 Farm income and nitrate leaching of three farm types in the Midi-Pyrénées region in France ${ }^{\mathrm{a}}$

\begin{tabular}{|c|c|c|c|c|}
\hline \multirow[t]{2}{*}{ Farm type } & \multicolumn{2}{|c|}{ Farm income (k€/year) } & \multicolumn{2}{|c|}{ Nitrate leaching ( $\left.\mathrm{kg} \mathrm{N}-\mathrm{NO}_{3}-/ \mathrm{ha}\right)$} \\
\hline & Baseline & $\begin{array}{l}\text { Nitrates } \\
\text { directive }^{\mathrm{b}}\end{array}$ & Baseline & Nitrates directive ${ }^{b}$ \\
\hline Large scale-medium intensity-arable cereal & 72 & 71 & 41 & 25 \\
\hline Large scale-medium intensity-arable fallow & 77 & 76 & 36 & 36 \\
\hline Large scale-medium intensity-arable (others) & 74 & 73 & 34 & 26 \\
\hline
\end{tabular}

${ }^{\mathrm{a}}$ A regional integrated assessment of the nitrate directive (adapted from Belhouchette and others 2010); ${ }^{\mathrm{b}}$ Experiment based on Nitrates directive (EC 1991) 


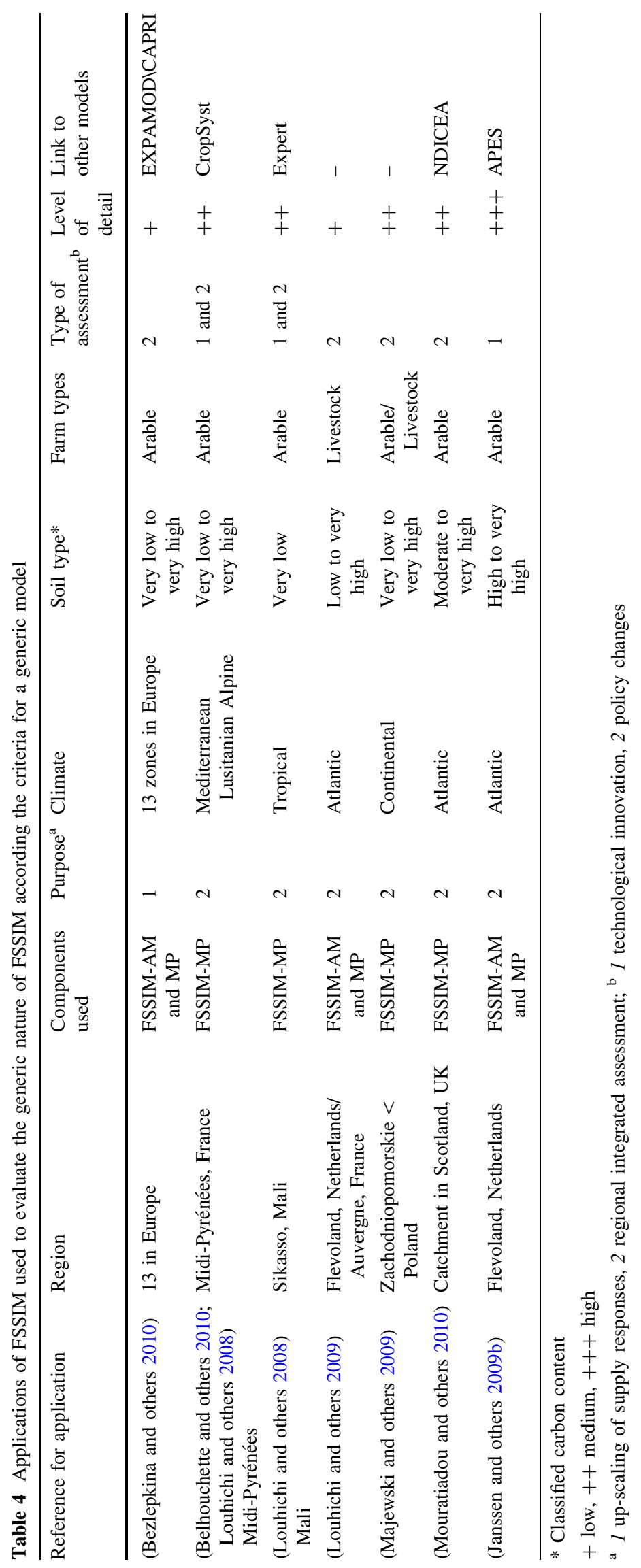


agri-environmental zones. An agri-environmental zone is a homogenous combination of soil and climate types, that covers parts or whole administrative regions. An example of such a definition of agri-environmental zone for the European Union can be found in Hazeu and others (2010). These biophysical conditions strongly affect the current farm structure, the farming possibilities and potential in a location and thus the specification of a BEFM. For example, for a highland area with only grazing a different configuration of the BEFM is required than for a lowland fertile area. FSSIM has been applied for different climate zones, e.g., Atlantic, Continental, Mediterranean, Lusitanian and Alpine and soil types e.g. sandy and clay soils.

The second criterion is that the BEFM must be applicable to a range of farm types, for example, arable, livestock and mixed farming systems, and low and high intensity systems as defined by a farm typology. Different farm types can be identified on the basis of a farm typology (Andersen and others 2007). The BEFM must have the capability to handle these different farm types consistently and without bias. FSSIM has been applied to a range of farm types (criterion 2) with different specializations (e.g., specialised crops based arable, cereal-based arable, livestock and mixed farms), different intensities (e.g., extensive and intensive farms) and different sizes (e.g., small sized farms in Mali and Zachodniopomorskie to large sized farms in Midi-Pyrénées). Although the same model base was used in these applications, each application has its peculiarities in configuration and quality due to the diversity in local conditions and data availability. FSSIM needs to be extended to be able to simulate farm types with perennial, intensive horticulture and intensive livestock systems. Intensive livestock (e.g., pigs, poultry) and horticulture (e.g., greenhouse production) systems are characterized by capital intensive, often landless and high external input use activities. FSSIM needs to be extended with constraints related to capital availability and an adapted definition of capital intensive activities for these farming systems. Extending FSSIM for perennial farming systems requires incorporating the temporal changes in perennial crops from a growing and establish crop to a productive crop. Another improvement required is to add standardized validation procedures to FSSIM, which can be applied if a user has the availability of different data set for calibration and validation.

The third criterion is the capability to address different purposes, e.g. assessments of technological innovations or policy issues (Janssen and Van Ittersum 2007). Assessments of policy issues have usually a short-term horizon and require realistic and validated modelling of farm responses, while assessments of technological innovations are explorative and often based on postulated optimal farm responses (Flichman and Jacquet 2003). With respect to criterion 3 , in most applications FSSIM has been used to assess the effects of policy changes and in two applications to assess the impact of technological innovations (Janssen and others 2009b; Louhichi and others 2008). FSSIM may be applied in the future to assess the impacts of societal or physical trends such as the effects of climate change and energy price increases on farm performance.

The fourth criterion is the capability to handle applications at different levels of detail in input or output data. Data availability will differ with the application, scale and location. For example, for regional studies often other types of data are available compared to an application at national or continental level. Moreover, accurate assessment of some indicators (e.g., landscape, biodiversity and greenhouse gas emissions) requires more detailed data on agricultural activities and their effects than that of other indicators (e.g., farmer income, total costs, revenues). The data requirements depend also on the purpose of the application and perspective of the researcher. In the various applications, different data sources, level of detail and model configurations have been used. In the application for micro-macro analysis the level of detail in data was lowest, as only regional data sources could be used that were standard available (Bezlepkina and others 2010). In the regional integrated assessment studies, more detailed data and specifications could be used, often by incorporating adhoc procedures (Belhouchette and others 2010; Louhichi and others 2009; Majewski and others 2009; Mouratiadou and others 2010). These ad-hoc procedures are not part of FSSIM per se and allow the modeller to combine his detailed data available regionally with local knowledge on soils and climate to compute specific technical coefficients for the regional conditions.

Finally, the fifth criterion is that it must be possible to link to a BEFM to different types of models simulating processes at different scales. Linking could be required to assess the impact of simulated land use changes on markets, bio-physical, structural or esthetical parameters of landscapes, and on emissions to water and air. For example, the up-scaling of farm responses to market level models is relevant for assessments of high level policies, while for assessments of biodiversity and landscape impacts of farming linking to landscape models is relevant. The BEFM should not be constrained in its linking to one specific type of model, but instead be capable to exchange input and output data with each of these model types in a flexible way. FSSIM has been linked to economic models (EXPAMOD/CAPRI) (Pérez Domínguez and others 2009) for up-scaling of its supply responses, but also to an environmental externality simulation model (NDICEA) and different cropping systems models (CropSyst and APES). A useful extension of the model linking is to link FSSIM to a landscape model, that allows to visualize or analyse the results of FSSIM at the landscape level. 
Not all components of FSSIM have been used in each application (Table 4). In some applications, both FSSIMAM and MP were used. In other applications only FSSIMMP was used in combination with other models and methods than FSSIM-AM to quantify farm activities. Individual components of FSSIM may also be used as stand alone tool, for example, the integrative component, crop component and risk component of FSSIM-MP (Table 1) to assess the response to changing risk on an arable farm or the livestock component of FSSIM-AM to calculate yearly feed requirements in terms of energy, protein and intake capacity of different farm animals. FSSIM needs to be configured depending on the data availability, research question and location. For example, to identify improved nitrogen fertilization techniques (rather than to simulate likely farm responses), FSSIM-AM components for both current and alternative activities need to be configured to include all potentially relevant production activities, and FSSIM-MP can be configured with a risk calibration procedure instead of PMP calibration. Alternatively, if the research question is to assess the short term effects of the abolishment of the EU set-aside policy, then the PMP calibration procedure of FSSIM-MP is required, but components for alternative activities in FSSIM-AM may not be needed as in the short term agricultural management is less likely to change significantly.

\section{Use and Extension of FSSIM}

FSSIM is available for use and extension, for new purposes, locations and scales, FSSIM will be maintained and extended as part of the SEAMLESS association (www. seamlessassociation.org) and is open source available on http://dev.seamless-if.org/svn/seamless-oss/trunk/models/. FSSIM would benefit from extensions to model biodiversity, landscape and conservation indicators, from procedures for sensitivity and uncertainty analysis, from a more detailed modeling of the relationships between livestock density, grassland and manure production and from further calibration and validation of the model to new locations and research questions.

The conceptual and technical integration of the different FSSIM components has proven to be a challenging and time-consuming task due to the complex data-types (or data-structures) being exchanged between components, the large data amounts and diverse data sources required to run FSSIM. The required investment in conceptual and technical integration might be a barrier to the initial development and maintenance of a generic BEFM. The division of FSSIM in components and tiers was useful to separate and group functionality, without lumping all functionality in one monolithic piece of source code with data. Making these components semantically aware (e.g., annotating them in an ontology) helped to clarify the data types exchanged between components, to integrate the different data sources, to create data repositories to manage these data in an adequate way and to link FSSIM in a transparent and explicit way to other models. To integrate new components into FSSIM, the following explicit integration procedure is proposed, which already has been used to integrate the livestock parts of FSSIM:

1. Conceptual development, implementation and testing of stand-alone component;

2. Enter component interfaces (e.g., inputs and outputs of the model) in an ontology and link to other ontologies;

3. Enter and check data in database based on the ontology;

4. Develop and test the wrapper of the component with the rest of FSSIM. The wrapper acts between components to translate data from one programming paradigm into another;

5. Make the tested and integrated component available in FSSIM;

6. Apply the integrated component to more regions, locations and experiments with new datasets.

This integration procedure can now be used to extend FSSIM with new components, e.g., for perennial activities, multi-functionality or intensive livestock systems. A technical barrier to the use of the FSSIM is the different programming paradigms used in components. Researchers are usually specialised in one programming paradigm. Training, user interfaces and documentation may help to overcome this barrier and generalists, who technically overlook FSSIM and its components, are required to maintain an overview.

In conclusion, FSSIM has been developed as a generic BEFM that targets wide applicability and models "generic" processes instead of specific processes to one research question, location or data source. FSSIM is a product from a joint development of agronomists and economists. This led to a fairly balanced definition between different types of activities, policy instruments and technological innovations, without emphasizing any in particular, to enable use of FSSIM for different study objectives. FSSIM can be easily maintained and extended, as it comprises individual components that can be extended and maintained independent from other components. Although a truly generic model may not be possible, FSSIM represents a first step in the development of a BEFM as a library of components and functionality that can be adapted to the purpose, scale and location of the application.

Acknowledgments This work has been carried out as part of the SEAMLESS Integrated Project, EU sixth Framework Programme, Contract No. 010036-2. We gratefully acknowledge access to the FADN data made available by EU-FADN-DG AGRI-A3 and funding 
received as part of the Knowledge Base program as part of the Ministry of Agriculture, Nature and Food of the Netherlands. We would like to thank two anonymous reviewers for the comments that helped to improve the article.

Open Access This article is distributed under the terms of the Creative Commons Attribution Noncommercial License which permits any noncommercial use, distribution, and reproduction in any medium, provided the original author(s) and source are credited.

\section{References}

Alkan Olsson J, Bockstaller C, Stapleton LM, Ewert F, Knapen R, Therond O, Geniaux G, Bellon S, Correira TP, Turpin N, Bezlepkina I (2009) A goal oriented indicator framework to support integrated assessment of new policies for agri-environmental systems. Environmental Science \& Policy 12:562-572

Andersen E, Elbersen B, Godeschalk F, Verhoog D (2007) Farm management indicators and farm typologies as a basis for assessments in a changing policy environment. Journal of Environmental Management 82:353

Athanasiadis IN, Janssen S (2008) Semantic mediation for environmental model components integration. Information Technologies in Environmental Engineering 1:3-11

Beaumont R, Dulphy JP, Sauvant D, Tran G, Mesch F, Aufrère J, Peyraud JL, Champciaux P (2007) Les tables de valeurs des aliments, Alimentation des Bovins, Ovins et Caprins. In: Quae (ed). Besoins des animaux valeurs des aliments, $476 \mathrm{pp}$

Belhouchette H, Louhichi K, Therond O, Mouratiadou I, Wery J, van Ittersum M, Flichman G (2010) Assessing the impact of the nitrate directive on farming systems using a bio-economic modelling chain. Agricultural Systems. doi:10.1016/j.agsy.2010. 09.003

Berentsen PBM (2003) Effects of animal productivity on the costs of complying with environmental legislation in Dutch dairy farming. Livestock Production Science 84:183-194

Bezlepkina I, Adenäeur $\mathrm{M}$, Kuiper $\mathrm{M}$, Janssen S, Knapen R, Kanellopoulos A, Brouwer F, Wien J-E, Wolf J, van Ittersum M (2010) Using the SEAMLESS integrated framework for exante assessment of trade policies. In: Trienekens J, Top J, Van der Vorst J, Beulens A (eds) Towards effective food chains: models and applications. Wageningen Academic Publishers, Wageningen, the Netherlands, pp 251-271

Confalonieri R, Bocchi S (2005) Evaluation of CropSyst for simulating the yield of flooded rice in northern Italy. European Journal of Agronomy 23:315-326

De Buck AJ, Hendrix EMT, Schoorlemmer HB (1999) Analysing production and environmental risks in arable farming systems: A mathematical approach. European Journal of Operational Research 119:416-426

Dogliotti S, Rossing WAH, van Ittersum MK (2003) ROTAT, a tool for systematically generating crop rotations. European Journal of Agronomy 19:239-250

Donaldson AB, Flichman G, Webster JPG (1995) Integrating agronomic and economic models for policy analysis at the farm level: the impact of CAP reform in two European regions. Agricultural Systems 48:163-178

Donatelli M, Russell G, Rizzoli AE, Acutis M, Adam M, Athanasiadis I, Balderacchi M, Bechini L, Belhouchette H, Bellocchi G, Bergez JE, Botta M, Braudeau E, Bregaglio S, Carlini L, Casellas E, Celette F, Ceotto E, Charron-Moirez ME, Confalonieri R, Corbeels M, Criscuolo L, Cruz P, Guardo AD, Ditto D, Dupraz C, Duru M, Fiorani D, Gentile A, Ewert F, Gary C,
Habyarimana E, Jouany C, Kansou K, Knapen MJR, Filippi GL, Leffelaar P, Manici L, Martin G, Martin P, Meuter EC, Mugueta N, Mulia R, van Noordwijk M, Oomen R, Rosenmund A, Rossi V, Salinari F, Serrano A, Sorce A, Vincent G, Theau JP, Therond O, Trevisan M, Trevisiol P, Van Evert FK, Wallach D, Wery J, Zerourou A (2010) APES: the agricultural production and externalities simulator In: Brouwer F, van Ittersum MK (eds) Environmental and agricultural modelling: integrated approaches for policy impact assessment. Springer Academic, New York, pp 63-108

Dorfman R, Samuelson PA, Solow RM (1958) Linear programming and economic analysis. McGraw-Hill, New York

EC (1991) Nitrates Directive 91/676/EEC. Commission, E. 91/676/ EEC

EC (2000) Directive 2000/60/EC of the European Parliament and of the Council, of 23 October 2000, establishing a framework for community action in the field of water policy. Commission, E. 22.12.2000

EC (2002) Implementation of Council Directive 91/676/EEC concerning the protection of waters against pollution caused by nitrates from agricultural sources-Synthesis from year 2000 Member States reports, pp

EC (2003) Council regulation (EC) No 1782/2003 of 29 September 2003. No1782/2003

EC (2007) Towards sustainable water management in the European Union-First stage in the implementation of the water framework directive 2000/60/EC-Communication from the Commission to the European Parliament and the Council, $13 \mathrm{pp}$

EC (2008a) Farm Accountancy Data Network (FADN) Source: EU-FADN-DG AGRI-G3. http://ec.europa.eu/agriculture/rica/. 15 Feb 2008

EC (2008b) Nomenclature of territorial units for statistics-NUTS Statistical Regions of Europe. http://ec.europa.eu/comm/ eurostat/ramon/nuts/home_regions_en.html. 15 Feb 2008

Evans E (2003) Domain-driven design: tackling complexity in the heart of software, 1st edn. Addison-Wesley Professional, Reading

Ewert F, van Ittersum MK, Bezlepkina I, Therond O, Andersen E, Belhouchette H, Bockstaller C, Brouwer F, Heckelei T, Janssen S, Knapen R, Kuiper M, Louhichi K, Alkan Olsson J, Turpin N, Wery J, Wien JE, Wolf J (2009) A methodology for integrated assessment of policy impacts in agriculture. Environmental Science \& Policy 12:546-561

Falconer K, Hodge I (2001) Pesticide taxation and multi-objective policy-making: farm modelling to evaluate profit/environment trade-offs. Ecological Economics 36:263-279

Feathers M (2004) Working effectively with legacy code. Prentice Hall PTR, Englewood Cliffs

Flichman G, Jacquet F (2003) Couplage des modèles agronomiques et économiques: intérêt pour l'analyse des politiques. Cahiers d'économie et sociologie rurales 67:1-20

Freund RJ (1956) The introduction of risk into a programming model. Econometrica 24:253-263

GAMS (2008) General algebraic modeling system (GAMS). http://www.gams.com/, accessed 8 April 2008

Gibson L, Kingwell R, Doole G (2008) The role and value of eastern star clover in managing herbicide-resistant crop weeds: a wholefarm analysis. Agricultural Systems 98:199-207

Gruber TR (1993) A translation approach to portable ontology specifications. Knowledge Acquisition 5:199-220

Hazell PBR, Norton RD (1986) Mathematical programming for economic analysis in agriculture. Macmillan Publishing Company, New York

Hazeu G, Elbersen B, Andersen E, Baruth B, van Diepen CA, Metzger MJ (2010) A biophysical typology for a spatiallyexplicit agri-environmental modeling framework. In: Brouwer F, 
Van Ittersum MK (eds) Environmental and agricultural modelling integrated approaches for policy impact assessment. Springer Academic, New York

Hengsdijk H, Van Ittersum MK (2002) A goal-oriented approach to identify and engineer land use systems. Agricultural Systems 71:231-247

Hengsdijk H, van Ittersum MK (2003) Formalizing agro-ecological engineering for future-oriented land use studies. European Journal of Agronomy 19:549-562

Hertel TW (1997) Global trade analysis: modeling and applications. Cambridge University Press, Cambridge, p 424

Howitt R (1995) Positive mathematical programming. American Journal of Agricultural Economics 77:329-342

Janssen S, Van Ittersum MK (2007) Assessing farm innovations and responses to policies: a review of bio-economic farm models. Agricultural Systems 94:622-636

Janssen S, Andersen E, Athanasiadis IN, Van Ittersum MK (2009a) A database for integrated assessment of European agricultural systems. Environmental Science \& Policy 12:573-587

Janssen S, Hengsdijk H, Oomen R, Van Ittersum MK (2009b) Agricultural management-module of FSSIM: procedures to generate and quantify alternative agricultural activities-production enterprise generator, production technique generator and technical coefficient generator-PD3.3.3, SEAMLESS integrated project, EU 6th Framework Programme, contract no. 010036-2, www.SEAMLESS-IP.org, accessed 31 October 2010, 108 pp. ISBN no. 978-90-8585-587-3

Jarrige R (1988) Alimentation des Bovins, Ovins et Caprins. INRA, Paris, p 476

Jarrige R (1989) Ruminant nutrition. Recommended allowances and feeding tables. INRA, Paris, p 389

Jarrige R, Demarquilly C, Dulphy JP, Hoden A, Robelin J, Beranger C, Geay Y, Journet M, Malterre C, Micol D, Petit M (1986) The INRA "fill unit" system for predicting the voluntary intake of forage-based diets in ruminants: a review. Journal of Animal Science 63:1737-1758

Kachele H, Dabbert S (2002) An economic approach for a better understanding of conflicts between farmers and nature conservationists-an application of the decision support system MODAM to the Lower Odra Valley National Park. Agricultural Systems 74:241-255

Kanellopoulos A, Berentsen PBM, Heckelei T, Van Ittersum MK, Oude Lansink AGJM (2010) Assessing the forecasting performance of a generic bio-economic farm model calibrated with two different PMP variants. Journal of Agricultural Economics 61:274-294

Keating BA, Carberry PS, Hammer GL, Probert ME, Robertson MJ, Holzworth D, Huth NI, Hargreaves JNG, Meinke H, Hochman Z, McLean G, Verburg K, Snow V, Dimes JP, Silburn M, Wang E, Brown S, Bristow KL, Asseng S, Chapman S, McCown RL, Freebairn DM, Smith CJ (2003) An overview of APSIM, a model designed for farming systems simulation. European Journal of Agronomy 18:267

Kingwell RS, Pannell DJ (1987) MIDAS, a bioeconomic model of a dryland farm system. Pudoc, Wageningen, p 207

Kingwell RS, Ghadim AKA, Robinson SD, Young JM (1995) Introducing Awassi sheep to Australia: an application of farming system models. Agricultural Systems 47:451-471

Knapen MJR, Verweij PJFM, Wien JJF (2007) Applying enterprise application architectures in integrated modelling. Proceedings of MODSIM, International Congress on Modelling and Simulation

Kopke E, Young J, Kingwell R (2008) The relative profitability and environmental impacts of different sheep systems in a Mediterranean environment. Agricultural Systems 96:85-94

Li H, Louhichi K, Janssen S, Rizzoli AE, Athanasiadis IN, Meuter E, Huber D (2007) Development and application of a component- based generic farm system simulator implementing a semantically enriched integrated modelling framework. In: Seventh international symposium on environmental software systems (ISESS-05), Prague, Czech Republic, IFIP,May 2007.

Louhichi K, Belhouchette H, Wery J, Therond O, Flichman G, Casellas E, Traoré B, Rapidel B, Barbier B, Lahmar R (2008) Application of FSSIM in two test case regions to assess agroenvironmental policies at farm and regional level. PD6.3.2.2, SEAMLESS integrated project, EU 6th Framework programme, contract no. 010036-2, www.SEAMLESS-IP.org, accessed 31 October 2010, $62 \mathrm{pp}$

Louhichi K, Hengsdijk H, Janssen S, Bigot G, Perret E (2009) EU dairy farming in the face of change: an exploration using a bioeconomic farm model. In: Proceedings of integrated assessment of agriculture and sustainable development: setting the agenda for policy and society (AgSap), Egmond aan Zee, www.seam lessassociation.org

Louhichi K, Janssen S, Li H, Borkowski N, Kanellopoulos A, Van Ittersum MK, Flichman G, Hengsdijk H, Zander P, Blanco M, Stokstad G, Athanasiadis I, Rizzoli AE, Huber D (2010a) A generic farming system simulator. In: Brouwer F, Van Ittersum MK (eds) Environmental and agricultural modelling integrated approaches for policy impact assessment. Springer Academic, New York, pp 109-132

Louhichi K, Kanellopoulos A, Janssen S, Flichman G, Blanco M, Hengsdijk H, Heckelei T, Berentsen P, Oude Lansink A, Ittersum MV (2010b) FSSIM, a bio-economic farm model for simulating the response of EU farming systems to agricultural and environmental policies. Agricultural Systems 103:585-597

Majewski E, Was A, Belhouchette H, Louhichi K, Mouratiadou I (2009) Impact assessment of policy changes on the arable sector using the FSSIM model: the case study of the Zachodniopomorskie NUTS2 region In: Proceedings of integrated assessment of agriculture and sustainable development: setting the agenda for policy and society (AgSap), Egmond aan Zee, www.seam lessassociation.org

McGuinness D, Van Harmelen F (2004) OWL web ontology language overview. www.w3.org/TR/owl-features/. 24 Jan 2008

Meuter E, Janssen S, Van Ittersum MK (2009) A graphical user interface for a generic bio-economic farm model (FSSIM). In: Proceedings of integrated assessment of agriculture and sustainable development: setting the agenda for policy and society (AgSap), Egmond aan Zee, www.seamlessassociation.org

Meyer-Aurich A, Zander P, Werner A, Roth R (1998) Developing agricultural land use strategies appropriate to nature conservation goals and environmental protection. Landscape and Urban Planning 41:119-127

Morrison DA, Kingwell RS, Pannell DJ, Ewing MA (1986) A mathematical programming model of a crop-livestock farm system. Agricultural Systems 20:243-268

Mouratiadou I, Russell G, Topp C, Louhichi K, Moran D (2010) Modelling common agricultural policy-water framework directive interactions and cost-effectiveness of measures to reduce nitrogen pollution. Water Science \& Technology 61:2689-2697

Oglethorpe DR, Sanderson RA (1999) An ecological-economic model for agri-environmental policy analysis. Ecological Economics 28:245-266

Onate JJ, Atance I, Bardaji I, Llusia D (2007) Modelling the effects of alternative CAP policies for the Spanish high-nature value cereal-steppe farming systems. Agricultural Systems 94:247-260

Oomen R, Hengsdijk H, Therond O, Bergez JE, Russell G, Casellas E, Janssen S, Van Ittersum MK (2009) Development of generic management rules for crop growth simulation models. In: Proceedings of integrated assessment of agriculture and sustainable development: setting the agenda for policy and society (AgSap), Egmond aan Zee, www.seamlessassociation.org 
Pacini GC (2003) An environmental-economic framework to support multi-objective policy-making : a farming systems approach implemented for Tuscany. PhD Thesis, Wageningen University, Wageningen, $173 \mathrm{pp}$

Pala M, Stockle CO, Harris HC (1996) Simulation of durum wheat (Triticum turgidum ssp durum) growth under different water and nitrogen regimes in a mediterranean environment using CropSyst. Agricultural Systems 51:147-163

Pérez Domínguez I, Bezlepkina I, Heckelei T, Romstad E, Oude Lansink A, Kanellopoulos A (2009) Linking farm and market models by means of response functions. Environmental Science \& Policy 12:588-601

Rizzoli AE, Donatelli M, Athanasiadis IN, Villa F, Huber D (2008) Semantic links in integrated modelling frameworks. Mathematics and Computers in Simulation 78:412-423

Röhm O, Dabbert S (2003) Integrating agri-environmental programs into regional production models: an extension of positive mathematical programming. American Journal of Agricultural Economics 85:254-265

Schuler J, Kachele H (2003) Modelling on-farm costs of soil conservation policies with MODAM. Environmental Science \& Policy 6:51-55

Stöckle CO, Martin SA, Campbell GS (1994) CropSyst, a cropping systems simulation model: water/nitrogen budgets and crop yield. Agricultural Systems 46:335-359

Stöckle CO, Donatelli M, Nelson R (2003) CropSyst, a cropping systems simulation model. European Journal of Agronomy 18:289-307

Szyperski C, Gruntz D, Murer S (2002) Component softwarebeyond object-oriented programming. ACM, New York

Ten Berge HFM, van Ittersum MK, Rossing WAH, van de Ven GWJ, Schans J (2000) Farming options for The Netherlands explored by multi-objective modelling. European Journal of Agronomy 13:263-277

Thorne PJ, Hengsdijk H, Janssen S, Louhichi K, van Keulen H, Thornton P (2008) Modelling livestock component in FSSIM. SEAMLESS Report no. 35, EU 6th Framework Programme, contract no. 010036-2, www.SEAMLESS-IP.org, accessed 31 October 2010, 65 pp, ISBN no. 90-8585-123-8 and 978-908585-123-3

Topp CFE, Mitchell M (2003) Forecasting the environmental and socio-economic consequences of changes in the common agricultural policy. Agricultural Systems 76:227-252
Uthes S, Sattler C, Reinhardt F-J, Piorr A, Zander P, Happe K, Damgaard M, Osuch A (2008) Ecological effects of payment decoupling in a case study region in Germany. Journal of Farm Management 13:219-230

Van der Burgt G, Oomen G, Habets A, Rossing W (2006) The NDICEA model, a tool to improve nitrogen use efficiency in cropping systems. Nutrient Cycling in Agroecosystems 74:275-294

Van Ittersum MK, Rabbinge R (1997) Concepts in production ecology for analysis and quantification of agricultural inputoutput combinations. Field Crops Research 52:197-208

Van Ittersum MK, Ewert F, Heckelei T, Wery J, Alkan Olsson J, Andersen E, Bezlepkina I, Brouwer F, Donatelli M, Flichman G, Olsson L, Rizzoli A, van der Wal T, Wien J-E, Wolf J (2008) Integrated assessment of agricultural systems-a component based framework for the European Union (SEAMLESS). Agricultural Systems 96:150-165

Vatn A, Bakken LR, Lundeby H, Romstad E, Rorstad PK, Vold A, Botterweg P (1997) Regulating nonpoint-source pollution from agriculture: an integrated modelling analysis. European Review of Agricultural Economics 24:207-230

Veldkamp A, Fresco LO (1996) CLUE-CR: an integrated multi-scale model to simulate land use change scenarios in Costa Rica. Ecological Modelling 91:231-248

Verburg PH, Soepboer W, Veldkamp A, Limpiada R, Espaldon V, Mastura SSA (2002) Modeling the spatial dynamics of regional land use: the CLUE-S model. Environmental Management 30:391-405

Wang Z-M, Zhang B, Li X-Y, Song K-S, Liu D-W, Zhang S-Q (2006) Using CropSyst to simulate spring wheat growth in black soil zone of northeast China. Pedosphere 16:354-361

Wossink GAA, Oude Lansink AGJM, Struik PC (2001) Nonseparability and heterogeneity in integrated agronomic-economic analysis of nonpoint-source pollution. Ecological Economics 38:345-357

Zander P, Kächele H (1999) Modelling multiple objectives of land use for sustainable development. Agricultural Systems 59:311-325

Zander P, Borkowski N, Hecker M, Uthes S, Stokstad G, Rørstad PK, Bellocchi G (2009) Conceptual approach to identify and assess current activities. SEAMLESS Report no. 50, SEAMLESS integrated project, EU 6th Framework Programme, contract no. 010036-2, www.SEAMLESS-IP.org, accessed 31 October 2010, 111 pp, ISBN no. 90-8585-118-1 and 978-90-8585-593-4 